• 研究报告・

\title{
喜马拉雅地区藤本植物多样性及其地理格局
}

\author{
胡 亮* \\ (中山大学地理科学与规划学院, 广州 510275)
}

\begin{abstract}
摘要: 喜马拉雅山地是生物地理学研究的热点地区之一。本文对喜马拉雅地区的藤本植物多样性及其与毗邻地区 的联系进行了统计分析, 并对该地区与印度河-恒河平原地区藤本植物多样性的地理格局及其成因进行了研究。结 果显示: (1)喜马拉雅地区总计有 1,083 种藤本植物, 分属72科309属; 其中木质藤本725种, 草质藤本358种; 攀援方 式主要为缠绕攀援 (51.3\%)。(2)该区域的藤本植物组成受相邻区域植物区系的显著影响, 其 1,083 种藤本植物中有 $74.1 \%$ (802种)在东南亚地区有分布, $50.6 \%$ (548种)在南亚有分布, $48.9 \%$ (530种)在中国西南地区有分布。本区藤本 植物缺乏特有性, 仅 125 种(11.5\%)为本区所特有, 没有特有含藤属。(3)藤本植物多样性及其在植物区系中的比例 均自东向西逐渐降低; 木质藤本比例和缠绕攀援藤本比例均自东向西略呈上升趋势; 大多数含藤属的藤本多样性 由东往西递减, 仅极少数含藤属由东往西逐渐增加, 如野踠豆属(Vicia) 和菟丝子属(Cuscuta)。(4)藤本植物多样性 在喜马拉雅和印度河-恒河平原地区呈现出自东向西递减的相似格局, 由东往西方向上含藤属递减率分别为8.4属 $/ 100 \mathrm{~km}$ 和6.3属/100 km, 但喜马拉雅地区藤本植物多样性更高。喜马拉雅和印度河-恒河平原地区均有分布的 272 个含藤属中有196属在中亚及伊朗高原不再有分布，其中 $31.1 \%$ (61属)在喜马拉雅地区的分布显著更偏西，仅 $4.1 \%$ (8属)在印度河一恒河平原的分布显著更偏西。综合分析表明, 喜马拉雅地区藤本植物的多样性及其地理格局的特 点与其特殊的地理位置、气候条件和生境的梯度变化以及毗邻地区植物区系的多元化有关; 水分条件的东西向梯 度变化可能是藤本植物在喜马拉雅和印度河一恒河平原地区形成相似格局的主要原因。
\end{abstract}

关键词: 木质藤本; 草质藤本; 攀援方式; 喜马拉雅地区; 印度河-恒河平原

\section{Diversity and distribution patterns of climbing plants in the Himalayan region}

Liang $\mathrm{Hu}^{*}$

Geography and Planning School, Sun Yat-Sen University, Guangzhou 510275

\begin{abstract}
The Himalayas are a biodiversity hotspot. In this study, the taxonomic diversity of climbing plants in the Himalayan region and its connection with neighbouring regions were analyzed, the distribution patterns of climbers in the Himalayas and the Indo-Gangetic Plain were compared, and mechanisms were discussed. Results showed that: (1) The Himalayan region harbored a total of 1,083 climbing species in 309 genera and 72 families. Approximately $66.9 \%$ ( 725 species) of these species were woody or semi-woody climbers (lianas) and the remaining $33.1 \%$ (358 species) were herbaceous (vines). Twining climbers accounted for $51.3 \%$ of the climbing plants in this region. (2) The climbing plant flora in the Himalayas was significantly affected by neighboring floras. About 74.1\% (802 species) of the climbers in the Himalayas were also found in Southeast Asia, 548 species (50.6\%) were found in South Asia, and 530 species (48.9\%) were found in Southwest China. Only 125 climbers (11.5\%) were endemic to this region and no endemic genus was recorded. (3) Species diversity of climbing plants and their proportion in the flora gradually decreased from east to west in the Himalayas. Twining climbers and lianas became more dominant in the western regions. At the genus level, species diversity of most climber-rich genera decreased westward across the Himalayas and species diversity of only a few genera (e.g. Vicia and Cuscuta) showed an increase from east to west. (4) The distribution patterns of climbing plants in the Himalayas and the Indo-Gangetic Plain were consistent. However, species diversity was higher in the
\end{abstract}

收稿日期: 2016-08-17; 接受日期: 2016-10-19

基金项目: 国家自然科学基金(41101057)

* 通讯作者 Author for correspondence. E-mail: huliang_hy@163.com 
Himalayas and its decreasing trend westward was more significant. At the genus level, the average decreasing rate of climber-containing genera from east to west is 8.4 genera per $100 \mathrm{~km}$ in the Himalayas and 6.3 genera per $100 \mathrm{~km}$ in the Indo-Gangetic Plain. A total of 272 climber-containing genera in the Himalayas were shared with the Indo-Gangetic Plain, and 196 genera were not found in the west regions (Central Asia and Iranian plateau). In the 196 genera, 61 genera (31.1\%) were distributed more to the west in the Himalayas than in the Indo-Gangetic Plain, while only 8 genera (4.1\%) were distributed more to the west in the Indo-Gangetic Plain than in the Himalayas. In conclusion, species diversity and distributional characteristics of climbers in the Himalayas were attributed in part to the geographical location of this region, the altitudinal and longitudinal gradients of climate and habitats, and the diversification of adjacent floras. The similarities of the distribution patterns of climbing plants in the Himalayas and the Indo-Gangetic Plain may be primarily due to similar east-west water gradients.

Key words: liana; vine; climbing method; Himalayan region; Indo-Gangetic Plain

山地往往在相对较小的距离内，因垂直梯度变 化而呈现出比低地、平原更为多样化的气候条件和 微生境, 有利于物种的生存, 因而物种多样性往往 更为丰富(McCain \& Grytnes, 2010; Spehn et al, 2010)。全球植物多样性中心包括许多山地, 如热带 亚热带安第斯山脉、高加索山脉、中国西南山地等 (Myers et al, 2000; Spehn et al, 2010)。喜马拉雅山脉 也是全球植物多样性热点地区之一, 长期以来因其 物种多样性、特有性以及地理格局而备受关注。由 于其独特的地理位置及周围毗邻地区生态环境的 显著差异, 喜马拉雅植物区系包含了许多不同的地 理成分：东亚成分，马来一缅甸成分，中国-日本成 分, 欧洲-地中海成分, 非洲成分, 西伯利亚成分等 (Singh \& Singh, 1987; Hajra et al, 1996)。在南北方向 上, 其植物区系和植被景观呈现出明显的垂直地带 性。例如, 在喜马拉雅东部地区，从低地到高山依 次发育着热带雨林，热带季雨林，常绿阔叶林，常绿 针叶林, 落叶针叶林, 落叶阔叶林, 亚高山常绿针叶 林，高山灌丛和草甸等植被类型; 植物区系中的热 带成分在低海拔地区占优势，东亚成分则在亚高山 和高山地带起主导作用(李恒和武素功, 1983; Hajra et al, 1996)。在东西方向上, 由于更新世的冰期对于 喜马拉雅东部影响有限，东部的环境在整个地质时 期都保持相对比较稳定的状态, 其物种多样性比喜 马拉雅西部更为丰富。东西方向上绵延 $2,500 \mathrm{~km}$ 连续 而渐变的气候和生境, 使得各种地理成分和生活型 的物种均能够在该地区找到适宜的分布区。

同其他许多生物类群一样，藤本植物多样性整 体上也在喜马拉雅地区呈现出明显的东西向变化 趋势(Srinivasan et al, 2014; Hu \& Li, 2015; Thakur \& Negi, 2015)。藤本植物是热带亚热带森林物种多样
性的重要组分, 在热带植物区系中其物种组成极为 丰富，在亚热带植物区系中亦占有十分重要的地 位，而在温带森林植物区系中所占比例不高 (Gentry, 1991; Hu et al, 2010; 胡亮, 2011; Hu \& Li, 2015)。因藤本植物通常导管更粗，受低温和干旱胁 迫的影响程度远比非藤本植物要大，故普遍认为水 热条件对藤本植物地理分布的影响极为显著 (Clinebell et al, 1995; Molina-Freaner et al, 2004; Schnitzer, 2005; Hu et al, 2010)。喜马拉雅地区主体 部分纬度跨度不大, 但初步研究显示藤本植物多样 性在其东西方向上的变化比东亚同纬度范围内的 其他地区更明显( $\mathrm{Hu} \& \mathrm{Li}, 2015)$; 推测这与喜马拉 雅地区降雨的东西向梯度变化以及毗邻植物区系 的特点有关。目前，仅有少量研究针对喜马拉雅地 区藤本植物的地理格局，且都是从垂直地带性的角 度加以探讨(Tanaka et al, 1983; Rawal \& Pangtey 1991; Barik et al, 2015), 而对整个喜马拉雅地区的 藤本植物区系特点及其东西方向上的地理格局未 见报道。

本文对喜马拉雅南坡地区种子植物区系中藤 本植物的组成、生活型和攀援方式的多样性进行了 统计分析，并从整体上对该地区与毗邻的东南亚、 南亚、中国西南、伊朗高原和中亚地区藤本植物区 系进行了比较。通过对藤本植物多样性及其组分由 东向西的梯度变化以及与印度河-恒河平原地区变 化趋势的比较，探讨了喜马拉雅地区藤本植物的地 理格局及其成因。

\section{1 研究方法}

\section{1 研究对象及其生态类型划分}

本文所指藤本植物(或攀援植物)为广义的藤本 
植物, 指能通过缠绕、卷须、吸器或蔓延搭靠等方 式依附于其他植物体实现纵向攀援生长, 并能超过 自身在无外界支持物条件下伸长极限的植物。本文 将在研究区域内至少含有一种藤本植物的科或属 特称为含藤科或含藤属, 在论及这些科属及其地理 分布时不包括相应科属中的非藤本植物。参照胡亮 等(2010), 依据茎干质地将藤本分为草质藤本(vine) 和木质藤本(liana); 依据攀援方式及其对潜在可用 支持物条件的利用特征将藤本归入缠绕藤本 (twining climber)、卷须藤本(tendrillar climber)、吸 附藤本 (adhesive climber) 和蔓生藤本 (sprawling climber) 4大类。对兼有多种攀援方式的藤本, 如具 卷须则归入卷须类, 无卷须但有不定根或吸器则归 入吸附类, 无以上特化器官但有明显缠绕行为的归 入缠绕类, 其他归入蔓生类。

\section{2 数据来源与分析}

藤本植物地理分布数据主要参考喜马拉雅及 其相邻地区和国家的植物志、植物名录以及大量的 研究专著和论文等区系资料汇编而成。科属系统参 照 APG III (The Angiosperm Phylogeny Group, 2009)。根据 The Plant List (2013)网络数据库 (http://www.theplantlist.org/) 对同物异名进行了校 正, The Plant List未收录的种名均根据较新的研究 资料确定, 少数涉及是否特有分布的关键类群均通 过最新的分类学论文加以判断或修订。

本文中对地区和区段的划分不完全依照行政 区划，某些地区或区段涉及多个行政区，为使文中 表述简练, 对这些地区或区段的实际范围和简称说 明如下: 本文研究的喜马拉雅地区包括东南段、不 丹段、尼泊尔段、北阿肯德段、喜马偕尔段和克什 米尔段6段。东南段主要包括我国西藏察隅、墨脱、 错那、隆子 4 县; 不丹段包括不丹、我国西藏亚东县 以及印度锡金邦和大吉岭; 尼泊尔段包括尼泊尔及 我国西藏吉隆、聂拉木、定日、定结4县的一部分; 北 阿肯德、喜马偕尔段均与印度行政区划范围对应; 克什米尔段包括巴控区和印控区。为揭示喜马拉雅 地区藤本植物组成和毗邻地区的联系, 将其与中国 西南地区、东南亚地区、南亚地区、伊朗高原和中 亚地区的藤本进行了比较。其中中国西南地区主要 包括云南(除西双版纳)、四川、西藏昌都以及林芝 北部; 东南亚地区包括缅甸、泰国、老挝、越南、 柬埔寨、云南西双版纳、印度东北部以及孟加拉国
的吉大港和锡尔赫特山地; 南亚地区包括印度的绝 大部分(除东北部及位于喜马拉雅的部分)、孟加拉 国(除吉大港和锡尔赫特)、斯里兰卡以及巴基斯坦 的平原部分; 伊朗高原地区包括伊朗、阿富汗以及 巴基斯坦的一部分; 中亚地区包括哈萨克斯坦、吉 尔吉斯斯坦、乌兹别克斯坦、土库曼斯坦、塔吉克 斯坦及新疆帕米尔高原。为了与喜马拉雅地区藤本 植物的分布格局进行对比，我们还将印度河一恒河 平原地区(含阿萨姆和梅加拉亚)进行了再划分, 由 东往西依次为阿萨姆段(含阿萨姆、梅加拉亚、孟加 拉国吉大港和锡尔赫特)、孟加拉段(包括孟加拉国 和印度西孟加拉的平原部分, 不包括大吉岭、吉大 港和锡尔赫特)、印度比哈尔邦、印度北方邦、印度 哈里亚纳段(含印度旁遮普邦)、巴基斯坦北部6段。

\section{2 结果}

\section{1 藤本植物多样性}

喜马拉雅地区种子植物区系中藤本植物种类 丰富。总计有 72 个含藤科 309 个含藤属 1,083 种藤本 植物; 分别占欧亚植物区系含藤科、属及藤本总种 数的 $71.3 \% 、 38.2 \%$ 和 $16.3 \%$ 。其中双子叶植物 62 科 288 属 984 种, 占总种数的 $90.9 \%$; 单子叶植物 9 科 20 属97种, 占 $8.9 \%$; 裸子植物仅买麻藤科 1 属 2 种, 占 $0.2 \%$ 。

全区木质藤本共 725 种，占总种数的 $66.9 \%$; 草 质藤本 358 种, 占总种数的 $33.1 \%$ 。在木质藤本所占 的比例上, 本区与毗邻的中国西南区 $(69.7 \%)$ 比较 接近, 低于东南亚(76.9\%)和南亚(74.4\%), 高于伊 朗高原 $(23.2 \%)$ 和中亚(18.7\%)。

\subsection{1 优势含藤科属}

在科水平上, 仅豆科和夹竹桃科在本区分布的 藤本植物超过 100 种; 旋花科、葫芦科和葡萄科的藤 本均不低于 50 种。上述 5 科仅占本区含藤科总数的 $6.8 \%$, 但其所含藤本种数占本区藤本总种数的 $42.8 \%$ 。藤本种类不低于 20 种的含藤科还有毛莨科、 茜草科等 10 个科, 共含藤本 295 种, 占本区藤本总 种数的 $27.2 \%$; 天南星科和菊科等 13 个科的藤本种 类不低于 10 种, 共占本区藤本总数的 $14.7 \%$; 使君 子科和大戟科等 17 个科的藤本种类不低于 5 种, 共 占 $10.3 \%$ 。余下 27 个含藤科的藤本数仅占本区藤本 总种数的 $5.0 \%$, 其中有 11 个科(如百部科、心翼果科 和远志科)仅含 1 种藤本(表 1 )。 
表1 喜马拉雅植物区系中各含藤科的藤本多样性

Table 1 Taxonomic composition of the families containing climbing plants in the Himalayan region

\begin{tabular}{|c|c|c|c|c|c|c|c|}
\hline 科名 Family & $\begin{array}{l}\text { 藤本总种数 } \\
\text { No. of climbers }\end{array}$ & $\begin{array}{l}\text { 草质藤本 } \\
\text { Vines }\end{array}$ & $\begin{array}{l}\text { 木质藤本 } \\
\text { Lianas }\end{array}$ & 科名 Family & $\begin{array}{l}\text { 藤本总种数 } \\
\text { No. of climbers }\end{array}$ & $\begin{array}{l}\text { 草质藤本 } \\
\text { Vines }\end{array}$ & $\begin{array}{l}\text { 木质藤本 } \\
\text { Lianas }\end{array}$ \\
\hline 豆科 Leguminosae & 162 & 75 & 87 & 胡颓子科 Elaeagnaceae & 6 & 0 & 6 \\
\hline 夹竹桃科 Apocynaceae & 124 & 25 & 99 & 唇形科 Lamiaceae & 6 & 0 & 6 \\
\hline 旋花科 Convolvulaceae & 69 & 52 & 17 & 木通科 Lardizabalaceae & 6 & 0 & 6 \\
\hline 葫芦科 Cucurbitaceae & 58 & 55 & 3 & 报春花科 Primulaceae & 6 & 0 & 6 \\
\hline 葡萄科 Vitaceae & 50 & 7 & 43 & 苦苍苔科 Gesneriaceae & 6 & 1 & 5 \\
\hline 毛茛科 Ranunculaceae & 46 & 5 & 41 & 天门冬科 Asparagaceae & 6 & 3 & 3 \\
\hline 茜草科 Rubiaceae & 42 & 27 & 15 & 西番莲科 Passifloraceae & 6 & 3 & 3 \\
\hline 蓄薇科 Rosaceae & 38 & 0 & 38 & 马钱科 Loganiaceae & 5 & 0 & 5 \\
\hline 胡椒科 Piperaceae & 28 & 1 & 27 & 猕猴桃科 Actinidiaceae & 4 & 0 & 4 \\
\hline 防已科 Menispermaceae & 27 & 7 & 20 & 叶下珠科 Phyllanthaceae & 4 & 0 & 4 \\
\hline 薯蓣科 Dioscoreaceae & 27 & 26 & 1 & 苋科 Amaranthaceae & 4 & 1 & 3 \\
\hline 鼠李科 Rhamnaceae & 25 & 0 & 25 & 爵床科 Acanthaceae & 4 & 3 & 1 \\
\hline 木犀科 Oleaceae & 21 & 0 & 21 & 紫草科 Boraginaceae & 3 & 0 & 3 \\
\hline 菝葜科 Smilacaceae & 21 & 0 & 21 & 菖麻科 Urticaceae & 3 & 0 & 3 \\
\hline 卫矛科 Celastraceae & 20 & 0 & 20 & 车前草科 Plantaginaceae & 3 & 3 & 0 \\
\hline 天南星科 Araceae & 19 & 0 & 19 & 牛栓藤科 Connaraceae & 2 & 0 & 2 \\
\hline 菊科 Compositae & 15 & 7 & 8 & 第伦桃科 Dilleniaceae & 2 & 0 & 2 \\
\hline 桑科 Moraceae & 14 & 0 & 14 & 买麻藤科 Gnetaceae & 2 & 0 & 2 \\
\hline 番荔枝科 Annonaceae & 13 & 0 & 13 & 莲叶桐科 Hernandiaceae & 2 & 0 & 2 \\
\hline 五加科 Araliaceae & 12 & 0 & 12 & 白花丹科 Plumbaginaceae & 2 & 0 & 2 \\
\hline 芸香科 Rutaceae & 12 & 0 & 12 & 檀香科 Santalaceae & 2 & 0 & 2 \\
\hline 龙胆科 Gentianaceae & 12 & 11 & 1 & 鸭跖草科 Commelinaceae & 2 & 2 & 0 \\
\hline 马㝸铃科 Aristolochiaceae & 11 & 5 & 6 & 无患子科 Sapindaceae & 2 & 2 & 0 \\
\hline 桔梗科 Campanulaceae & 11 & 11 & 0 & 茄科 Solanaceae & 2 & 2 & 0 \\
\hline 棕榈科 Arecaceae & 10 & 0 & 10 & 漆树科 Anacardiaceae & 1 & 0 & 1 \\
\hline 山柑科 Capparaceae & 10 & 0 & 10 & 绣球科 Hydrangeaceae & 1 & 0 & 1 \\
\hline 禾本科 Poaceae & 10 & 0 & 10 & 铁青树科 Olacaceae & 1 & 0 & 1 \\
\hline 蓼科 Polygonaceae & 10 & 8 & 2 & 山柚子科 Opiliaceae & 1 & 0 & 1 \\
\hline 使君子科 Combretaceae & 9 & 0 & 9 & 泡桐科 Paulowniaceae & 1 & 0 & 1 \\
\hline 金虎尾科 Malpighiaceae & 8 & 0 & 8 & 远志科 Polygalaceae & 1 & 0 & 1 \\
\hline 罂粟科 Papaveraceae & 7 & 7 & 0 & 心翼果科 Cardiopteridaceae & 1 & 1 & 0 \\
\hline 茶茉英科 Icacinaceae & 7 & 0 & 7 & 石竹科 Caryophyllaceae & 1 & 1 & 0 \\
\hline 清风藤科 Sabiaceae & 7 & 0 & 7 & 秋水仙科 Colchicaceae & 1 & 1 & 0 \\
\hline 五味子科 Schisandraceae & 7 & 0 & 7 & 兰科 Orchidaceae & 1 & 1 & 0 \\
\hline 锦葵科 Malvaceae & 7 & 1 & 6 & 百部科 Stemonaceae & 1 & 1 & 0 \\
\hline 大戟科 Euphorbiaceae & 7 & 3 & 4 & 总计 Total & 1,083 & 358 & 725 \\
\hline 忍冬科 Caprifoliaceae & 6 & 0 & 6 & & & & \\
\hline
\end{tabular}

属的水平上，本区藤本种数最丰富的前 6 个属 依次为铁线莲属 (Clematis, 41种)、悬钩子属(Rubus, 33种)、胡椒属(Piper, 28种)、薯蓣属(Dioscorea, 27 种)、茉莉属(Jasminum, 20种)和拢葜属(Smilax, 20 种); 它们仅占本区含藤属总数的 $1.9 \%$, 但所含藤 本种数占本区藤本总种数的 $15.6 \%$ 。除上述 6 属外, 另有 21 属在本区的藤本种数不低于 10 种, 依次为崖
爬藤属(Tetrastigma，17种)、银背藤属(Argyreia，16 种)、球兰属(Hoya, 15种)、野踠豆属(Vicia, 15种)、 菟丝子属(Cuscuta, 14种)、番薯属(Ipomoea, 14种)、 崖角藤属 (Rhaphidophora，12 种)、鱼黄草属 (Merremia , 12种)、鱼藤属(Derris, 12种)、吊灯花属 (Ceropegia, 12种)、马兒铃属(Aristolochia, 11种)、拉 拉藤属 (Galium, 11种)、党参属(Codonopsis, 11种)、 
榕属(Ficus, 11种)、茜草属(Rubia，11种)、栝楼属 (Trichosanthes，10种)、羊蹄甲属(Bauhinia，10种)、 娃儿藤属(Tylophora, 10种)、鹿蒦属(Rhynchosia, 10 种)、葛属(Pueraria, 10种)和白粉藤属(Cissus, 10种)。 另外, 山柑属(Capparis)、我鸟线藤属(Cynanchum)等 41 个含藤属的藤本种类不低于 5 种; 山牵牛属 (Thunbergia)、猕猴桃属(Actinidia) 等40个含藤属的 藤本种类不低于 3 种; 买麻藤属 $($ Gnetum $) 、$ 榼藤属 (Entada) 等57属仅含 2 种藤本。余下 144 个含藤属在 本区均只分布有 1 种藤本(如帽儿瓜属 $(M u k i a)$ 、微花 藤属(Iodes)、帘子藤属(Pottsia) 等), 分别占含藤属和 藤本总种数的 $46.6 \%$ 和 $13.3 \%$; 单种藤本的含藤属 主要来自夹竹桃科(28属)、豆科(17属)、葫芦科(13 属)和防己科(10属)。

\subsection{2 攀援方式}

如表2所示，喜马拉雅地区藤本植物的攀援方 式主要为缠绕攀援, 其次为蔓生攀援和卷须攀援, 吸附攀援的种类最少。

缠绕攀援藤本共556种, 包括本区过半 (51.3\%) 的藤本种类。以缠绕攀援为主的含藤科主要包括豆 科(129种)、夹竹桃科(108种)、旋花科(55种)、毛茛 科(45种)和防已科(27种)。优势含藤属依次为铁线莲 属(41种)、薯蓣属(27种)和银背藤属(16种)。

蔓生攀援藤本共 270 种, 占本区藤本总种数的 $24.9 \%$ 。其中的优势含藤科包括蓄薇科(38种)、茜草 科(30种)和鼠李科(25种)。蓄薇科悬钩子属(33种)的 藤本种类最为丰富, 其次为拉拉藤属和茜草属, 各 11 种。

卷须攀援藤本共 177 种, 占本区藤本总种数的 $16.3 \%$ 。其中的优势含藤科主要为葫芦科(58种)和葡 萄科(49种), 豆科(26种)和菝契科(21种)也有不少种 类以卷须攀援。优势含藤属依次为菝荰属 $(20$ 种)、 崖爬藤属(17种) 和野豌豆属(15种); 此外, 栝楼属、 羊蹄甲属和白粉藤属也均有 10 种卷须藤本。

吸附攀援藤本共 80 种, 仅占 $7.4 \%$ 。以不定根攀 援的胡椒科(28种)和天南星科(19种)的吸附类藤本 最多; 优势含藤属包括胡椒属(28种)、崖角藤属(12 种)、榕属(11种)以及以吸器结合缠绕攀援的菟丝子 属(14种)。

\section{2 藤本植物地理格局}

\subsection{1 喜马拉雅地区与周边地区的比较}

喜马拉雅地区的藤本组成显著受相邻区域植
物区系的影响，尤其是东南亚、南亚和中国西南区 系, $99.7 \%$ 的含藤属和 $86.3 \%$ 的藤本种类在东南亚、 南亚或中国西南地区也有分布。

东南亚是亚洲藤本植物最为丰富的地区(97科 621 属3,449种)。喜马拉雅地区的 72 个含藤科全都在 东南亚有藤本分布; 除鹰嘴豆属(Cicer)、旋花豆属 (Cochlianthus) 等 12 属外, 其余的 297 个含藤属 $(96.1 \%)$ 在东南亚也均有藤本分布; 喜马拉雅 1,083 种藤本植物中有 802 种 $(74.1 \%)$ 在东南亚地区有分 布。在亚洲大陆地区，薯预属、胡椒属、崖爬藤属、 茉莉属、番薯属和球兰属均以东南亚最为丰富, 这 些属在喜马拉雅地区的藤本也相对较丰富(表3)。

南亚地区藤本多样性虽然不如东南亚，但也较 喜马拉雅地区丰富(86科410属1,386种), 且南亚毗 邻喜马拉雅, 因此两个地区间联系也十分密切。除 莲叶桐科、泡桐科、菖麻科和绣球科外, 喜马拉雅 地区其余 68 个含藤科在南亚也均有藤本分布; 喜马 拉雅地区243个含藤属 $(78.6 \%)$ 和 548 种藤本 $(50.6 \%)$ 在南亚也有分布。喜马拉雅地区的优势含藤属中, 银背藤属的多样性中心在南亚(表3), 但南亚比喜马 拉雅地区缺失包括首乌属(Fallopia)、土采儿属 (Apios)、蔓龙胆属(Crawfurdia) 等在内的66属。

中国西南地区的一部分属泛喜马拉雅范畴，与 本文所论述喜马拉雅地区的植物区系联系密切, 藤 本植物区系(79科332属1,746种)中仅缺失秋水仙科; 此外, 麻核藤属(Natsiatopsis)、藤芋属(Scindapsus)、 预腊藤属(Goniostemma)、倒吊兰属(Erythrorchis)、 鹰嘴豆属等68属也未在中国西南分布, 喜马拉雅地 区241 个含藤属 $(78.0 \%)$ 和 530 种藤本 $(48.9 \%)$ 在中国 西南地区也有分布。中国藤本植物区系中铁线莲 属、县钩子属和菝契属藤本都极为丰富, 在中国西 南地区也依旧保持较高的多样性, 并对喜马拉雅地 区的藤本植物区系产生显著的影响(表3)。

除个别类群外, 伊朗高原和中亚地区整体上对 喜马拉雅地区的藤本组成影响不大。一方面, 由于 藤本植物多样性由东向西递减, 至克什米尔段藤本 植物多样性已大为降低, 含藤科、含藤属和藤本种 类仅 30 科93属 179 种。另一方面, 藤本植物多样性水 平在中亚地区(20科34属134种)和伊朗高原地区(22 科49属155种)也非常低。因此, 尽管喜马拉雅地区 的藤本植物类群在伊朗高原 $(12.0 \%$ 的含藤属和 $5.5 \%$ 的藤本种类 $)$ 和中亚地区 $(8.7 \%$ 的含藤属和 $5.0 \%$ 
表2 喜马拉雅种子植物区系中藤本植物不同攀援方式的多样性及其比例(\%)

Table 2 Subdivision of climbing plants and their proportions (\%) in the spermatophyte flora of the Himalayan region

\begin{tabular}{lllll}
\hline 地区 District & 缠绕藤本 Twining climbers & 卷须藤本 Tendrillar climbers & 吸附藤本 Adhesive climbers 蔓生藤 & $\begin{array}{c}\text { S } \\
\text { climbrawling }\end{array}$ \\
\hline 东南段 SE. Himalaya & $312(48.6)$ & $109(17.0)$ & $59(9.2)$ & $162(25.2)$ \\
不丹段 Bhutan & $317(53.6)$ & $94(15.9)$ & $29(4.9)$ & $151(25.5)$ \\
尼泊尔段 Nepal & $276(55.0)$ & $90(17.9)$ & $21(4.2)$ & $115(22.9)$ \\
北阿肯德段 Uttarakhand & $183(53.7)$ & $63(18.5)$ & $21(6.2)$ & $74(21.7)$ \\
喜马偕尔段 Himachal & $123(60.6)$ & $46(22.7)$ & $7(3.4)$ & $27(13.3)$ \\
克什米尔段 Kashmir & $103(57.5)$ & $33(18.4)$ & $12(6.7)$ & $31(17.3)$ \\
总计 Total & $556(51.3)$ & $177(16.3)$ & $80(7.4)$ & $270(24.9)$ \\
\hline
\end{tabular}

表3 喜马拉雅及其毗邻地区藤本最为丰富的含藤属及其种数 ${ }^{*}$

Table 3 The most climber-rich genera in the Himalayan region and its neighbouring regions

\begin{tabular}{|c|c|c|c|c|c|}
\hline 喜马拉雅 Himalaya & 东南亚 SE. Asia & 南亚 S. Asia & 中国西南 SW. China & 伊朗高原 Iranian Plateau & 中亚 C. Asia \\
\hline 铁线莲属 Clematis (41) & 省藤属 Calamus (87) & 银背藤属 Argyreia (39) & 铁线莲属 Clematis (68) & 野踠豆属 Vicia (30) & 菟丝子属 Cuscuta (31) \\
\hline 悬钩子属 Rubus (33) & 薯蓣属 Dioscorea (83) & 番薯属 Ipomoea (37) & 悬钩子属 Rubus (65) & 菟丝子属 Cuscuta (21) & 野踠豆属 Vicia (21) \\
\hline 胡椒属 Piper (28) & 胡椒属 Piper (74) & 吊灯花属 Ceropegia (30) & 菝契属 Smilax (53) & 山黧豆属 Lathyrus (16) & 山黧豆属 Lathyrus (15) \\
\hline 薯蓣属 Dioscorea (27) & 崖爬藤属 Tetrastigma (66) & 省藤属 Calamus (29) & 薯蓣属 Dioscorea (39) & - & - \\
\hline 茉莉属 Jasminum (20) & 茉莉属 Jasminum (61) & 胡椒属 Piper (29) & 胡椒属 Piper (32) & - & - \\
\hline 菝葜属 Smilax (20) & 羊蹄甲属 Bauhinia (61) & 铁线莲属 Clematis (25) & 马兒铃属 Aristolochia (32) & - & - \\
\hline 崖爬藤属 Tetrastigma (17) & 银背藤属 Argyreia (59) & 茉莉属 Jasminum (24) & 猕猴桃属 Actinidia (31) & - & - \\
\hline 银背藤属 Argyreia (16) & 悬钩子属 Rubus (56) & 薯蓣属 Dioscorea (22) & 茉莉属 Jasminum (29) & - & - \\
\hline 球兰属 Hoya (15) & 菝契属 Smilax (53) & 山柑属 Capparis (21) & 崖爬藤属 Tetrastigma (29) & - & - \\
\hline 野踠豆属 Vicia (15) & 球兰属 Hoya (48) & 鹿蕉属 Rhynchosia (20) & 雪胆属 Hemsleya (29) & - & - \\
\hline 番薯属 Ipomoea (14) & 番薯属 Ipomoea (44) & 黄檀属 Dalbergia (21) & 栝楼属 Trichosanthes (27) & - & - \\
\hline 菟丝子属 Cuscuta (14) & 鱼藤属 Derris (41) & 崖爬藤属 Tetrastigma (20) & 党参属 Codonopsis (23) & - & - \\
\hline
\end{tabular}

* 伊朗高原和中亚地区藤本种类低于 10 种的含藤属未列出。

* Genera with less than 10 climbers in Iranian Plateau and Central Asia were not list.

的藤本种类)的分布比例均很低，但在本区西部各 段的藤本总数中所占比重很高, 在一定程度上影响 了喜马拉雅西部的藤本区系构成。例如，伊朗高原 和中亚地区植物区系中藤本最多的两个属都是菟 丝子属和野踠豆属, 种类均超过20种(表3); 而该两 属在克什米尔分别有 11 种和 10 种藤本, 仅次于铁线 莲属(12种), 合占克什米尔藤本总数的 $11.7 \%$ 。其他 一些藤本不甚丰富的中亚、伊朗高原或地中海成分 对喜马拉雅地区西部的组成也有一定的影响, 如山 黧豆属(Lathyrus)和鹰嘴豆属。

\subsection{2 喜马拉雅地区藤本植物的地理分布}

对喜马拉雅地区 1,083 种藤本在喜马拉雅 $(\mathrm{A})$ 及 其相邻区域南亚 $(B) 、$ 东南亚 $(C)$ 、中国西南(D)、伊 朗高原或中亚(E)的分布情况进行了统计(表4), 结 果表明, 喜马拉雅地区藤本植物的地理分布具有以 下特点:
(1)东南亚、南亚和中国西南植物区系的影响贯 穿整个喜马拉雅地区。喜马拉雅地区 1,083 种藤本 中，524种(48.4\%)在南亚以及喜马拉雅以东( $\mathrm{ABC}$ 、 $A B D 、 A B C D)$ 均有分布; 若加上广布种 $(A B(C D) E)$ 和其他分布略窄的成分 $(A B 、 A C 、 A D 、 A C D)$, 这 一比例高达 $84.6 \%$ 。

(2)缺乏特有性。本区没有特有含藤属, 仅 125 种藤本 $(11.5 \%)$ 为本区所特有，低于相邻的南亚 $(33.8 \%)$ 、东南亚 $(28.5 \%)$ 和中国西南 $(15.2 \%)$ 。特有 藤本种类较丰富的属主要包括悬钩子属 $(10$ 种)、铁 线莲属(9种)、胡椒属(6种)、吊灯花属(6种)和马兒 铃属(5种)。

(3)伊朗高原和中亚成分的影响局限于喜马拉 雅西部, 对克什米尔的影响较为显著。仅在喜马拉 雅及其以西分布 $(\mathrm{AE})$ 的种类只有 21 种，如高大蒬丝 子(Cuscuta gigantea)、Rubia himalayensis和 
表4 喜马拉雅地区1,083种藤本植物在该区域各段的分布格局

Table 4 Distribution patterns of the 1,083 Himalayan climbing species in different part of the Himalayan region

\begin{tabular}{llllllll} 
分布 & 藤本总数 & 克什米尔 & 喜马偕尔 & 北阿肯德 & 尼泊尔段 & 不丹段 & 东南段 \\
Distribution & Climbers & Kashmir & Himachal & Uttarakhand & Nepal & Bhutan & SE. Himalaya \\
\hline $\mathrm{ABCD}$ & $286(26.4)$ & $43(24.0)$ & $64(31.5)$ & $127(37.2)$ & $191(38.0)$ & $228(38.6)$ & $219(34.1)$ \\
$\mathrm{ABC}$ & $227(21.0)$ & $38(21.2)$ & $45(22.2)$ & $82(24.0)$ & $102(20.3)$ & $134(22.7)$ & $118(18.4)$ \\
$\mathrm{ACD}$ & $127(11.7)$ & - & $2(1.0)$ & $14(4.1)$ & $47(9.4)$ & $50(8.5)$ & $102(15.9)$ \\
$\mathrm{A}$ & $125(11.5)$ & $10(5.6)$ & $12(5.9)$ & $24(7.0)$ & $48(9.6)$ & $52(8.8)$ & $49(7.6)$ \\
$\mathrm{AC}$ & $100(9.2)$ & $3(1.7)$ & $3(1.5)$ & $4(1.2)$ & $13(2.6)$ & $41(6.9)$ & $72(11.2)$ \\
$\mathrm{AD}$ & $65(6.0)$ & $2(1.1)$ & $3(1.5)$ & $8(2.3)$ & $18(3.6)$ & $15(2.5)$ & $49(7.6)$ \\
$\mathrm{AB}(\mathrm{CD}) \mathrm{E}$ & $57(5.3)$ & $35(19.6)$ & $36(17.7)$ & $39(11.4)$ & $44(8.8)$ & $33(5.6)$ & $19(3.0)$ \\
$\mathrm{AB}$ & $43(4.0)$ & $10(5.6)$ & $13(6.4)$ & $21(6.2)$ & $17(3.4)$ & $22(3.7)$ & $5(0.8)$ \\
$\mathrm{AE}$ & $21(1.9)$ & $19(10.6)$ & $6(3.0)$ & $2(0.6)$ & $2(0.4)$ & $1(0.2)$ & - \\
$\mathrm{ABE}$ & $13(1.2)$ & $11(6.1)$ & $9(4.4)$ & $7(2.1)$ & $4(0.8)$ & $1(0.2)$ & - \\
$\mathrm{ABD}$ & $11(1.0)$ & $2(1.1)$ & $6(3.0)$ & $8(2.3)$ & $10(2.0)$ & $10(1.7)$ & $6(0.9)$ \\
$\mathrm{A}(\mathrm{CD}) \mathrm{E}$ & $7(0.6)$ & $5(2.8)$ & $4(2.0)$ & $5(1.5)$ & $6(1.2)$ & $4(0.7)$ & $3(0.5)$ \\
$\mathrm{AF}$ & $1(0.1)$ & $1(0.6)$ & - & - & - & - & -
\end{tabular}

A：喜马拉雅; B: 南亚; C: 东南亚; D: 中国西南; $(\mathrm{CD})$ : 东南亚或中国西南; E: 伊朗高原或中亚; F: 非洲。

A, Himalaya; B, South Asia; C, Southeast Asia; D, Southwest China; (CD), Southeast Asia or Southwest China; E, Iranian Plateau or Central Asia; F, Africa.

Vincetoxicum canescens; 喜马拉雅、南亚及其以西 分布 $(\mathrm{ABE})$ 的种类只有 13 种, 如单柱菟丝子 (Cuscuta monogyna)、藏西铁线莲(Clematis graveolens)和Cynanchum acutum; 喜马拉雅及其以西和以 东均有分布而在南亚缺失 $(\mathrm{A}(\mathrm{CD}) \mathrm{E})$ 的种有7个: 蔓 首乌(Fallopia convolvulus)、猪殊殊(Galium spurium)、欧白英(Solanum dulcamara)、三角叶薯蓣 (Dioscorea deltoidea)、牧地山黧豆 (Lathyrus pratensis)、野踠豆(Vicia sepium) 和甘青铁线莲 (Clematis tangutica)。另外, 有一种呈非洲-喜马拉 雅间断分布(AF), 即Merremia palmata, 该种在非洲 广布，而在亚洲仅克什米尔地区有记录。

\section{3 藤本植物地理格局}

\subsection{1 喜马拉雅地区藤本植物的梯度变化}

喜马拉雅地区藤本植物多样性自东向西逐渐 降低的整体趋势明显。在由东往西的 6 个段中, 含藤 科、含藤属和藤本种数均自东向西逐渐递减(表 5); 种子植物区系中藤本种数及其在植物区系中所占 比例 $(\mathrm{CPF})$ 依次为642 $(13.0 \%) 、 591(10.8 \%) 、 502$ $(9.8 \%) 、 341(8.0 \%) 、 203(6.0 \%)$ 和179 (4.2\%)。

不同生态类型藤本植物在喜马拉雅地区也呈 东西向的明显变化。随着藤本植物多样性在自东向 西的 6 个分段中的整体下降, 一方面, 喜马拉雅自 东向西各段中木质藤本的比例逐渐递减, 而草质藤 本比例相应上升(表5); 另一方面, 缠绕攀援藤本的
比例大致呈上升趋势; 蔓生攀援藤本比例呈下降趋 势; 而卷须和吸附攀援的比例变化均不明显(表2)。

此外, 不同分类群的藤本在喜马拉雅东西向的 变化趋势存在差异。科的水平上, 各科自东向西均 呈递减趋势; 豆科和夹竹桃科在喜马拉雅自东向西 6 个段中虽也呈递减趋势, 但在各段均为藤本多样 性最丰富的两个科; 在东南段和不丹段, 葫芦科的 藤本多样性均列第三; 而在尼泊尔、北阿肯德和克 什米尔段中旋花科排在第三; 喜马偕尔则以毛茛科 排在第三。属的水平上, 大多数属的藤本多样性由 东往西递减, 如悬钩子属、胡椒属、薯蓣属、菝葜 属、球兰属等; 而少数属则由东往西逐渐增加, 如 野踠豆属和菟丝子属(表6)。

\subsection{2 喜马拉雅与印度河一恒河平原地区的比较}

与喜马拉雅地区的格局类似, 藤本植物多样性 在印度河-恒河平原地区也呈现出东西向递减的趋 势，但两个地区之间存在一些差别。在印度河-恒河 平原地区由阿萨姆、孟加拉、比哈尔、北方邦、哈 里亚纳至巴基斯坦北部6段, 相应的藤本植物种数 及其 $\mathrm{CPF}$ 依次为 $917(15.4 \%) 、 467(13.8 \%) 、 320$ (13.0\%)、295 (11.4\%)、123 (11.8\%)和68 (3.5\%), CPF 递减梯度不如喜马拉雅地区明显。

与印度河一恒河平原相比, 喜马拉雅地区含藤 属自东向西减少的趋势更为显著和均匀。喜马拉雅 地区分布的 309 个含藤属中, 有 233 属在克什米尔以 
表5 喜马拉雅各段藤本植物多样性

Table 5 Climbing plant diversity in different part of the Himalayan region

\begin{tabular}{llllll}
\hline 地区 District & 科 Family & 属 Genus & 种 Species & 草质藤本 Vines (\%) & 木质藤本 Lianas (\%) \\
\hline 东南段 SE. Himalaya & 69 & 239 & 642 & $178(27.7)$ & $464(72.3)$ \\
不丹段 Bhutan & 67 & 235 & 591 & $185(31.3)$ & $406(68.7)$ \\
尼泊尔段 Nepal & 62 & 195 & 502 & $176(35.1)$ & $326(64.9)$ \\
北阿肯德段 Uttarakhand & 54 & 157 & 341 & $125(36.7)$ & $216(63.3)$ \\
喜马偕尔段 Himachal & 35 & 105 & 203 & $98(48.3)$ & $105(51.7)$ \\
克什米尔段 Kashmir & 30 & 93 & 179 & $83(46.4)$ & $96(53.6)$ \\
总计 Total & 72 & 309 & 1,083 & $358(33.1)$ & $725(66.9)$ \\
\hline
\end{tabular}

表6 喜马拉雅地区藤本种数最为丰富的前 12 个含藤属及其藤本分布

Table 6 Distribution of the 12 most climber-rich genera in the Himalayan region

\begin{tabular}{|c|c|c|c|c|c|c|c|}
\hline 属名 Genus & $\begin{array}{l}\text { 藤本种数 } \\
\text { Climbers }\end{array}$ & $\begin{array}{l}\text { 克什米尔段 } \\
\text { Kashmir }\end{array}$ & $\begin{array}{l}\text { 喜马偕尔段 } \\
\text { Himachal }\end{array}$ & $\begin{array}{l}\text { 北阿肯德段 } \\
\text { Uttarakhand }\end{array}$ & $\begin{array}{l}\text { 尼泊尔段 } \\
\text { Nepal }\end{array}$ & $\begin{array}{l}\text { 不丹段 } \\
\text { Bhutan }\end{array}$ & $\begin{array}{l}\text { 东南段 } \\
\text { SE. Himalaya }\end{array}$ \\
\hline 铁线莲属 Clematis & 41 & 12 & 16 & 17 & 27 & 16 & 21 \\
\hline 悬钩子属 Rubus & 33 & 0 & 1 & 6 & 17 & 21 & 18 \\
\hline 胡椒属 Piper & 28 & 0 & 0 & 4 & 6 & 11 & 22 \\
\hline 薯蓣属 Dioscorea & 27 & 3 & 5 & 9 & 12 & 9 & 26 \\
\hline 茉莉属 Jasminum & 20 & 5 & 2 & 8 & 9 & 12 & 15 \\
\hline 菝萑属 Smilax & 20 & 2 & 4 & 10 & 13 & 12 & 15 \\
\hline 崖爬藤属 Tetrastigma & 17 & 1 & 1 & 6 & 11 & 13 & 11 \\
\hline 银背藤属 Argyreia & 16 & 2 & 1 & 4 & 8 & 10 & 6 \\
\hline 球兰属 Hoya & 15 & 2 & 1 & 3 & 4 & 12 & 10 \\
\hline 野踠豆属 Vicia & 15 & 10 & 11 & 7 & 6 & 4 & 4 \\
\hline 菟丝子属 Cuscuta & 14 & 10 & 3 & 4 & 3 & 3 & 5 \\
\hline 番薯属 Ipomoea & 14 & 3 & 3 & 7 & 9 & 3 & 2 \\
\hline
\end{tabular}

西的中亚及伊朗高原不再有藤本分布，平均每往西 $100 \mathrm{~km}$ 减少 8.4 个含藤属, 其中以北阿肯德段的减 少速率最快(图1); 自东向西6个段减少的含藤属比 例依次占减少总数的 $20.5 \% 、 17.9 \% 、 17.9 \% 、 19.7 \%$ 、 $7.7 \%$ 和 $16.2 \%$ 。喜马拉雅地区分布的 309 个含藤属中 有 272 属在印度河一恒河平原也有藤本分布, 其中 196属在巴基斯坦北部以西不再有藤本分布，平均 每往西 $100 \mathrm{~km}$ 减少 6.3 个含藤属, 其中以孟加拉段 的减少速率最快; 自东向西 6 个段减少的含藤属比 例依次为 $28.6 \% 、 19.9 \% 、 12.8 \% 、 25.0 \% 、 11.7 \%$ 和 $2.0 \%$ (图1)。

含藤属在喜马拉雅地区的分布西界整体上比 印度河-恒河平原更偏西。喜马拉雅地区和印度河恒河平原以西不再有藤本分布的196个含藤属中, 有61属(31.1\%)在喜马拉雅地区的藤本分布西界比 在印度河-恒河平原的分布显著更靠西(图1)。例如, 共有 56 个含藤属在阿萨姆以西的印度河-恒河平原
不再有藤本分布，而其中肖拢荰属(Heterosmilax)、 班果藤属(Stixis)等6个属在喜马拉雅地区可分布至 尼泊尔段, 土臬儿属和蓬莱葛属(Gardneria) 等 8 个 属可往西延伸至北阿肯德段; 胡颓子属 (Elaeagnus)、绞股蓝属(Gynostemma) 等4属往西延伸 至喜马偕尔段。再如，鱼藤属、清风藤属(Sabia)等 17 个含藤属在印度河-恒河平原分布至北方邦段, 而在喜马拉雅地区可继续往西延伸至克什米尔段。 藤本分布西界较为接近的地方主要集中在两处: 一 处为喜马拉雅东南段-阿萨姆以西(共26属, 如构属 (Broussonetia)、倒吊兰属(Erythrorchis)、尖花藤属 (Friesodielsia) 和须药藤属(Stelmocrypton)); 另一处 为北阿肯德-北方邦以西(共16属, 如胡椒属、猕猴 桃属和黄檀属(Dalbergia)。仅 8 个含藤属 $(4.1 \%)$ 在印 度河-恒河平原的分布西界比在喜马拉雅地区的分 布显著更靠西，例如鰿藤属(Anodendron)和盒子草 属(Actinostemma)均仅在喜马拉雅的东南段分布, 


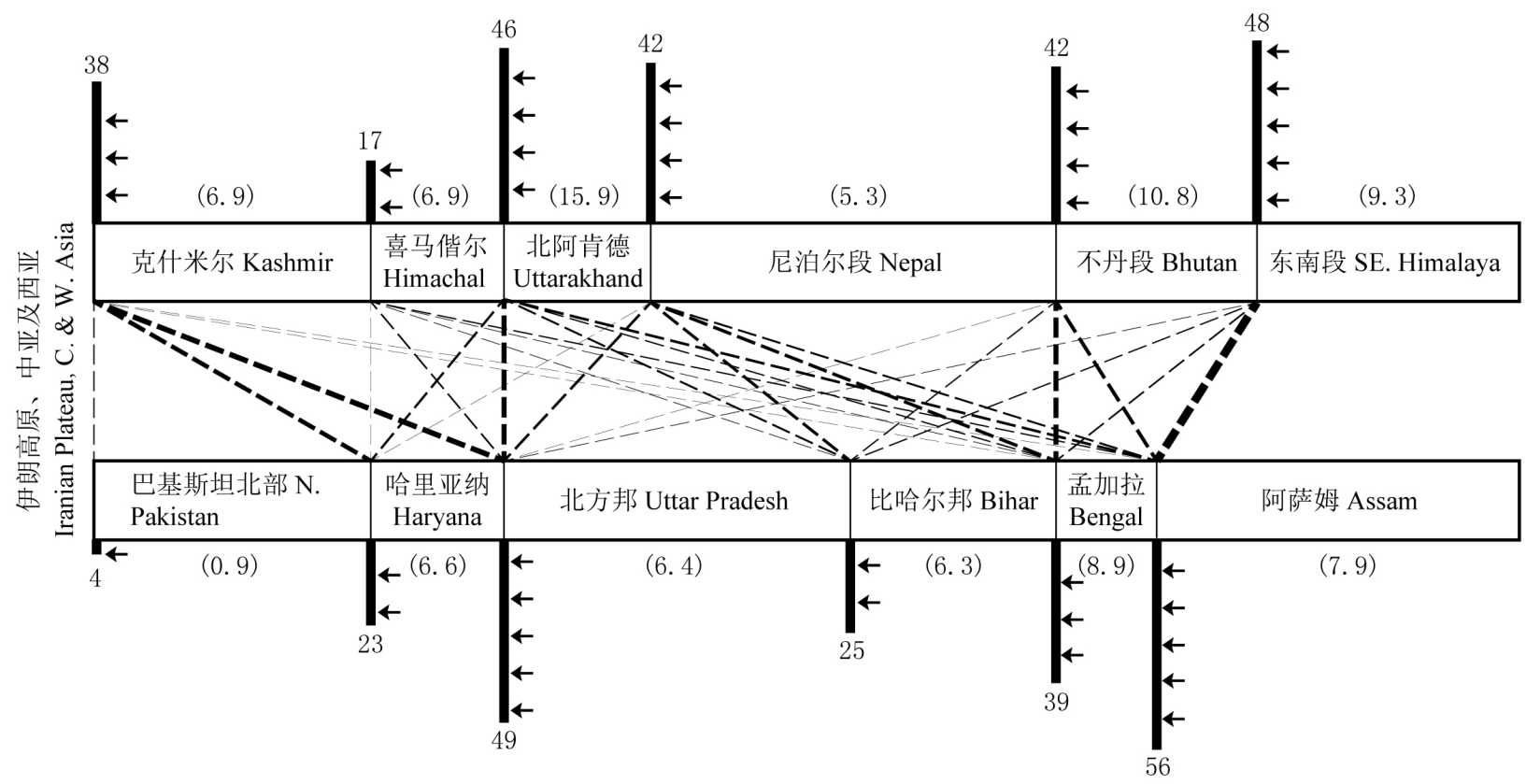

图1 喜马拉雅和印度河-恒河平原地区含藤属的分布西界。黑色柱及其末端数字代表在其西侧各区段再无藤本分布的含藤属 数量, 括号中的数字表示在各区段中平均往西100 $\mathrm{km}$ 减少的含藤属数, 虚线表示同一含藤属分布西界在喜马拉雅和印度河恒河平原地区的对应模式, 虚线越粗表明该模式下的含藤属数量越多。

Fig. 1 West distribution boundaries of the climber-containing genera in the Himalayas and the Indo-Gangetic Plain. Black columns denote the number of climber-containing genera disappeared in the west sections. Numbers in brackets denote reduced climber-containing genera per $100 \mathrm{~km}$ to the west in each section. Dashed lines denote the west distribution boundaries in the Himalayas and the Indo-Gangetic Plain. The width of the dashed line corresponds to the number of genera following this model.

而在印度河-恒河平原，前者往西分布至比哈尔邦， 后者往西分布至北方邦。

\section{3 讨论}

\section{1 喜马拉雅地区藤本植物区系的特点}

喜马拉雅地区藤本植物区系最鲜明的特点是 缺乏特有性, 没有真正意义上的特有含藤属。喜马 拉雅地区植物的特有性一直以来都备受关注, 该区 没有特有科, 而对特有属的研究往往都比较零散, 未见较全面的报道。Ahmedullah (2000)列举了喜马 拉雅东部和西部所特有的 67 个属; Mitra和 Mukherjee (2007) 列举了56个特有或近特有属; Manchester等(2009)列举了喜马拉雅东部30个特有 属。作者对这些属的地理分布及其系统发育分析进 行了重新整理, 发现存在较大出入。一方面, 随着 周边地区植物区系调查的深入和资料的积累，一些 原本认为分布局限于喜马拉雅地区的属在其他地 区也有发现。例如, Ahmedullah (2000)的名录中至少 有 27 属不是喜马拉雅特有属, 如短瓣花属 (Brachystemma) 和鞭打绣球属 (Hemiphragma); Mitra
和Mukherjee (2007)的名录中也至少有 16 个属的分 布区远超出了喜马拉雅的范围, 如石丁香属 (Neohymenopogon)和紫花苣苔属(Loxostigma) 等。另 一方面, 系统发育学研究取缔或归并了一些特有 属, 这种情况在含有藤本植物的属中尤为突出。例 如, Ahmedullah (2000)以及Mitra和Mukherjee (2007) 的特有属名录中都包括 3 个含有藤本植物的单型属: 藏瓜属(Indofevillea)、三裂瓜属(Biswarea) 和三棱瓜 属(Edgaria)。藏瓜属原只有藏瓜 (I. khasiana) 一种, 分布于喜马拉雅东南段、不丹段和阿萨姆, 但近来 在缅甸东北部发现一新种I. jiroi (Schaefer et al, 2012)。三裂瓜属和三棱瓜属在系统发育树中和另一 单型属波棱瓜属(Herpetospermum)的关系十分紧密 (Kocyan et al, 2007), Schaefer和Renner (2011)将前 两属并入波棱瓜属。再加上2014年报道的新种 $H$. operculatum (Pradheep et al, 2014), 上述各属均已不 再为喜马拉雅特有属。Mitra和Mukherjee (2007)的 特有属名录中还包括单型属互叶铁线莲属 (Archiclematis), 但系统发育学研究表明该属应归入 铁线莲属(Miikeda et al, 2006; Xie et al, 2011)。上文 
提及的 3 份特有属名录中均保留了夹竹桃科单型属 Treutlera, 仅T. insignis一种; 该种在梅加拉亚也有 分布(Jagtap \& Singh，1999), 而且基于Surveswaran (2014)对该属及其近缘属的系统发育学研究结果, 该属很有可能应归入匙美藤属 (Gymnema)。另外, 树萝卜属(Agapetes)植物虽在喜马拉雅东部、中国西 南和东南亚均有分布, 但多为附生灌木; 而《西藏 植物志》第3卷(吴征镒，1986)和《中国植物志》第 57 卷(方瑞征等，1991)等文献均记载分布于喜马拉 雅东南段的锈毛树萝卜 (A. anonyma) 多少具攀援习 性。该种的标本极为有限, 有关植物志的记载均译 自该种正式发表的拉丁文描述(Airy-Shaw，1948), 我们对照拉丁原文及作者的说明, 判定该种不属本 文的藤本研究范畴。因此, 可以说喜马拉雅地区没 有真正意义上的特有含藤属。

受毗邻地区的影响显著是喜马拉雅地区藤本 植物区系的另一个特点。除下文将要提到的喜马拉 雅地区内部生态环境多样化的原因外, 决定喜马拉 雅地区藤本植物格局的一个重要基础是毗邻地区 生态环境的多元化。东南亚地区是亚洲藤本植物多 样性中心, 热带成分显著; 东亚地区的藤本植物也 十分丰富, 如中国特有含藤属就有14属(胡亮等, 2010); 南亚藤本植物种类略逊于东亚, 但特有性较 高( $\mathrm{Hu} \& \mathrm{Li}, 2015)$; 中亚和伊朗高原虽藤本种类不 多, 但菟丝子属和野踠豆属藤本较亚洲其他地区 多。因此, 喜马拉雅东部的藤本植物组成受东南亚 和中国西南植物区系的影响显著; 西部的藤本植物 组成除依然受东南亚和中国西南植物区系的影响 外, 还与毗邻的伊朗高原和中亚植物区系联系密 切, 显示出与欧洲-地中海植物区系的亲缘性; 而 喜马拉雅中部的藤本植物组成还明显受南亚植物 区系的影响。

\section{2 喜马拉雅地区藤本植物地理格局的影响因素}

生物类群的地理格局往往受到历史和生态因 素的综合作用(Srinivasan et al, 2014)。尽管藤本植物 的最早化石记录可追溯至中泥盆世吉维期, 但种子 植物中的藤本植物最早可能出现于早白严纪, 并在 始新世才开始繁盛起来(Burnham, 2015)。彼时, 正 值喜马拉雅运动第一幕(陈祥高, 1979), 古地中海的 变迁和青藏高原的隆起对喜马拉雅地区植物区系 及其发展都有着深远的影响。然而, 喜马拉雅植物 区系中子遗植物和特有性的缺乏, 以及早第三纪之
前化石记录的缺失等证据均表明喜马拉雅植物区 系是较年轻的 (Singh \& Singh, 1987; 张宏达等, 1988; 孙航, 2002)。因此，现代喜马拉雅地区藤本植 物区系及其地理格局的主要成因应该是生态的，而 非历史的。在末次盛冰期，喜马拉雅除东部以外的 其余部分均为冰川所覆盖(Srinivasan et al，2014); 冰川退却后，各相邻地区植物区系中的藤本植物和 其他生物类群才得以在喜马拉雅地区传播和扩散, 逐渐形成其现有格局。

生态环境因子对喜马拉雅地区的藤本植物地 理格局的作用可通过与印度河－恒河平原的对比看 出。喜马拉雅地区的藤本植物所呈现出的自东向西 递减的趋势，大致与哺乳类、鸟类、昆虫等其他类 群的多样性在喜马拉雅地区的变化趋势一致 (Srinivasan et al, 2014; Thakur \& Negi, 2015)。在其 东西方向上藤本植物 $\mathrm{CPF}$ 指数的降低幅度比亚洲相 同纬度范围内的地区要大 $(\mathrm{Hu}$ et al, 2010; Hu \& Li, 2015)。不仅如此, CPF及含藤属沿喜马拉雅地区自 东向西的递减趋势比印度河一恒河平原更为均匀, 且同属藤本植物在喜马拉雅地区的分布西界更靠 西。一方面，藤本植物格局的相似性表明东南亚和 中国西南地区的藤本往西扩散的过程在喜马拉雅 地区和印度河一恒河平原同时发生; 另一方面，格 局差异性的形成与喜马拉雅独特的地形、水分和植 被等要素密切相关。

喜马拉雅地区热量的变化主要体现在垂直梯 度上，东西方向上在相同海拔范围内的热量差异不 甚明显。西部的克什米尔、喜马偕尔和北阿肯德的 低海拔地段热量依然充足, 发育有热带密灌从, 其 中藤本植物包括羊蹄甲属、白花叶属(Poranopsis)、 锡生藤属(Cissampelos)、盾翅藤属(Aspidopterys)、 风筝果属(Hiptage)等热带成分(Hajra et al，1996)。 Rawal和Pangtey (1991)对喜马拉雅中部山地藤本植 物的研究结果显示, 以东南亚为多样性中心的类群 (如云实属(Caesalpinia)、黄檀属、榕属、藤芋属)多 分布在海拔800-1,000 $\mathrm{m}$ 以下，而以东亚为藤本多样 性中心的类群多分布在海拔800-1,000 $\mathrm{m}$ 以上(如铁 线莲属、猕猴桃属、悬钩子属和菩薇属); 48 种常绿藤 本中仅2种在 $2,500 \mathrm{~m}$ 以上有分布，而在 $2,500 \mathrm{~m}$ 以上 仍有分布的落叶藤本达 12 种。由此可见，沿海拔梯度 的热量变化和生境的多样化是各种成分藤本植物在 喜马拉雅地区共存的重要原因之一。 
水分条件自东向西的梯度变化可能是在喜马 拉雅和印度河一恒河平原地区形成相似的藤本植物 多样性梯度变化的主要原因。藤本植物的地理格局 显著受到水热条件的限制(Hu et al, 2010)。如前所 述, 热量的差异主要影响藤本植物的垂直梯度分 布, 而水分条件的差异主要影响藤本植物的东西向 分布。一方面, 在喜马拉雅和印度河一恒河平原地 区, 降水量均沿东西方向整体上呈递减趋势, 而且 西部地区冬季的降雨比例大于东部地区, 克什米尔 地区的气候更类似于地中海地区。另一方面, 喜马 拉雅不丹段以西各段的降水量都比印度河一恒河平 原相应段高。例如, 喜马拉雅海拔1,500-2,000 m范 围内的年降水量在其东部约 $4,000 \mathrm{~mm}$, 中部约 $2,000 \mathrm{~mm}$, 而西部约 1,000-1,900 mm (Singh \& Singh, 1987; Hajra et al, 1996); 而相应的印度河-恒 河平原降水量在东部阿萨姆、孟加拉约1,500-2,500 $\mathrm{mm}$, 比哈尔降水量勉强超过 $1,000 \mathrm{~mm}$, 而北方邦 及其往西在500-1,000 mm之间(Hajra et al, 1996)。因 此, 整体上同属藤本植物在喜马拉雅地区的分布比 在印度河-恒河平原更靠西, 且不丹段及其以西各 段的藤本植物多样性均比印度河一恒河平原相应段 要高。

人类活动对藤本植物的现状格局也有一定的 影响。由于水分条件相对较好、人类活动干扰强度 相对较低, 喜马拉雅地区森林植被的发育和保存都 比印度河-恒河平原地区要好(Hajra et al, 1996)。印 度河-恒河平原是南亚文明的发源地, 其绝大部分 的原生植被都因粗放型的农业活动而变为密灌从 或疏林(Hajra et al, 1996; Kumar, 2001), 例如比哈尔 邦的森林覆盖率仅 $16.81 \%$, 且密林比例不足一半 (Singh et al, 2001)。在上恒河平原保存相对较好的 密林中依然有丰富的藤本植物和蔓性竹类, 例如在 北方邦戈勒克布尔的森林中藤豆腐柴(Premna scandens)、石岩枫(Mallotus repandus)、短柱铁线莲 (Clematis cadmia)、Uvaria hamiltonii 等十分常见 (Hajra et al, 1996)。藤本植物的攀援习性是在与直立 植物的竞争中发展起来的, 其适生生境也是以森林 植被为最佳, 故其在喜马拉雅地区各段的物种丰富 度比印度河一恒河平原要高。

\section{参考文献}

Ahmedullah M (2000) Endemism in the Indian flora. In: Flora of India: Introductory Volume (Part II) (eds Singh NP,
Singh DK, Hajra PK, Sharma BD), pp. 246-265. Botanical Survey of India, Calcutta.

Airy-Shaw HK (1948) Studies in the Ericales, V. Further notes on Agapetes. Kew Bulletin, 3, 77-104.

Barik SK, Adhikari D, Chettri A, Singh PP (2015) Diversity of lianas in Eastern Himalayas and North-Eastern India. In: Biodiversity of Lianas (ed. Parthasarathy N), pp. 99-122. Springer, Switzerland.

Burnham RJ (2015) Climbing plants in the fossil record: Paleozoic to present. In: Ecology of Lianas (eds Schnitzer SA, Bongers F, Burnham RJ, Putz FE), pp. 205-220. John Wiley \& Sons, Ltd., West Sussex.

Chang HT, Kong YC, But PH (1988) The origin and its affinity of the Nepalese flora. Acta Scientiarum Naturalium Universitatis Sunyatseni, 27(2), 1-12. (in Chinese with English abstract) [张宏达, 江润祥, 毕培曦 (1988) 尼泊尔植物区系 的起源及其亲缘关系. 中山大学学报(自然科学版), 27(2), $1-12$.

Chen XG (1979) K-Ar Dating and division of the Himalayan movement in southern Xizang. Scientia Geologica Sinica, 14(1), 13-21. (in Chinese with English abstract) [陈祥高 (1979) 西藏南部同位素地质年龄的测定与喜马拉雅运动 的分期. 地质科学, 14(1), 13-21.]

Clinebell RR, Phillips O, Gentry AH, Stark N, Zuuring H (1995) Prediction of neotropical tree and liana species richness from soil and climatic data. Biodiversity and Conservation, 4, 56-90.

Fang RC, Hsu TZ, Huang SH, Gao BC (1991) Flora Reipublicae Popularis Sinicae, Volume 57(3). Science Press, Beijing. (in Chinese) [方瑞征, 徐廷志, 黄素华, 高宝莼 (1991) 中国植物志, 第57卷第3分册. 科学出版社, 北京]

Gentry A (1991) The distribution and evolution of climbing plants. In: The Biology of Vines (eds Putz FE, Mooney HA), pp. 3-52. Cambridge University Press, Cambridge.

Hajra PK, Sharma BD, Sanjappa M, Sastry ARK (1996) Flora of India: Introductory Volume (Part I). Botanical Survey of India, Calcutta.

$\mathrm{Hu}$ L (2011) Distribution and diversity of climbing plants in temperate East Asia. Biodiversity Science, 19, 567-573. (in Chinese with English abstract) [胡亮 (2011) 东亚温带藤 本植物多样性及其格局. 生物多样性, 19, 567-573.]

$\mathrm{Hu}$ L, Li MG (2015) Diversity and distribution of climbing plants in Eurasia and North Africa. In: Biodiversity of Lianas (ed. Parthasarathy N), pp. 57-79. Springer, Switzerland.

Hu L, Li MG, Li Z (2010) The diversity of climbing plants in the spermatophyte flora of China. Biodiversity Science, 18, 198-207. (in Chinese with English abstract) [胡亮, 李鸣光, 李贞 (2010) 中国种子植物区系中的藤本多样性. 生物 多样性, 18, 198-207.]

Hu L, Li M, Li Z (2010) Geographical and environmental gradients of lianas and vines in China. Global Ecology and Biogeography, 19, 554-561.

Jagtap AP, Singh NP (1999) Fascicles of Flora of India, Fascicle 24. Botanical Survey of India, Calcutta. 
Kumar S (2001) Flora of Haryana (Materials). Bishen Singh Mahendra Pal Singh, Dehra Dun.

Li H, Wu SK (1983) The regionalization of Xizang (Tibet) flora and the floristic structure of south Himalaya region. Acta Geographica Sinica, 38, 252-261. (in Chinese with English abstract) [李恒, 武素功 (1983) 西藏植物区系区 划和喜马拉雅南部植物地区的区系特征. 地理学报, 38 , 252-261.]

Manchester SR, Chen ZD, Lu AM, Uemura K (2009) Eastern Asian endemic seed plant genera and their paleogeographic history throughout the Northern Hemisphere. Journal of Systematics and Evolution, 47, 1-42.

McCain CM, Grytnes JA (2010) Elevational gradients in species richness. In: Encyclopedia of Life Sciences. John Wiley $\&$ Sons Ltd., Chichester.

Mitra S, Mukherjee SKR (2007) Reassessment and diversity of endemic angiospermic genera of India. Journal of Economic and Taxonomic Botany, 31, 163-176.

Miikeda O, Kita K, Handa T, Yukawa T (2006) Phylogenetic relationships of Clematis (Ranunculaceae) based on chloroplast and nuclear DNA sequences. Botanical Journal of the Linnean Society, 152, 153-168.

Molina-Freaner F, Gamez RC, Tinoco-Ojanguren C, Castellanos AE (2004) Vine species diversity across environmental gradients in northwestern Mexico. Biodiversity and Conservation, 13, 1853-1874.

Myers N, Mittermeier RA, Mittermeier CG, Fonseca GAB, Kent J (2000) Biodiversity hotspots for conservation priorities. Nature, 403, 853-858.

Pradheep K, Pandey A, Bhatt KC, Nayar ER (2014) Herpetospermum operculatum (Schizopeponeae, Cucurbitaceae), a new species from India, Myanmar and China. Blumea, 59, $1-5$.

Rawal RS, Pangtey PS (1991) Distribution and phenology of climbers of Kumaun in central Himalaya, India. Vegetatio, 97, 77-87.

Schaefer H, Bartholomew B, Boufford DE (2012) Indofevillea jiroi (Cucurbitaceae), a new floral oil producing species from northeastern Myanmar. Harvard Papers in Botany, 17, 323-332.

Schaefer H, Renner SS (2011) Phylogenetic relationships in the order Cucurbitales and a new classification of the gourd family (Cucurbitaceae). Taxon, 60, 122-138.

Schnitzer SA (2005) A mechanistic explanation for global patterns of liana abundance and distribution. The American Naturalist, 166, 262-276.
Singh NP, Mudgal V, Khanna KK, Srivastava SC, Sahoo AK, Bandopadhyay S, Aziz N, Das M, Bhattacharya RP, Hajra PK (2001) Flora of Bihar: Analysis. Botanical Survey of India, Calcutta.

Singh JS, Singh SP (1987) Forest vegetation of the Himalaya. Botanical Review, 53, 80-192.

Spehn EM, Rudmann-Maurer K, Körner C, Maselli D (2010) Mountain Biodiversity and Global Change. Global Mountain Biodiversity Assessment of Diversitas, Basel.

Srinivasan U, Tamma K, Ramakrishnan U (2014) Past climate and species ecology drive nested species richness patterns along an east-west axis in the Himalaya. Global Ecology and Biogeography, 23, 52-60.

Sun H (2002) Tethys retreat and Himalayas-Hengduanshan Mountains uplift and their significance on the origin and development of the Sino-Himalayan elements and alpine flora. Acta Botanica Yunnanica, 24, 273-288. (in Chinese with English abstract) [孙航 (2002) 古地中海退却与喜马 拉雅-横断山的隆起在中国喜马拉雅成分及高山植物区 系的形成与发展上的意义. 云南植物研究, 24, 273-288.]

Surveswaran S, Sun M, Grimm GW, Liede-Schumann S (2014) On the systematic position of some Asian enigmatic genera of Asclepiadoideae (Apocynaceae). Botanical Journal of the Linnean Society, 174, 601-619

Tanaka N, Ohsawa M, Numata M (1983) Ecology of climbing plants in east Nepal. In: Ecological Studies in the Arun Valley, East Nepal and Mountaineering of Mt. Baruntse, 1981 (ed. Numata M), pp. 129-138. Chiba University, Chiba.

Thakur ML, Negi V (2015) Status and phylogenetic analyses of endemic birds of the Himalayan region. Pakistan Journal of Zoology, 47, 417-426.

The Angiosperm Phylogeny Group (2009) An update of the Angiosperm Phylogeny Group classification for the orders and families of flowering plants: APG III. Botanical Journal of the Linnean Society, 161, 105-121.

Wu CY (1986) Flora Xizangica, Volume 3. Science Press, Beijing. (in Chinese) [吴征镒 (1986) 西藏植物志, 第3卷. 科 学出版社, 北京]

Xie L, Wen J, Li LQ (2011) Phylogenetic analyses of Clematis (Ranunculaceae) based on sequences of nuclear ribosomal ITS and three plastid regions. Systematic Botany, 36, 907-921. 